\title{
Quantitative MRI of the wrist and nerve conduction studies in patients with idiopathic carpal tunnel syndrome
}

\author{
S Uchiyama, T Itsubo, T Yasutomi, H Nakagawa, M Kamimura, H Kato
}

J Neurol Neurosurg Psychiatry 2005;76:1 103-1 108. doi: 10.1136/jnnp.2004.051060

See end of article for authors' affiliations .....................

Correspondence to: Dr S Uchiyama, Director, Department of

Orthopaedic Surgery,

Suwa Red Cross Hospital,

Suwa City, 392-8510,

Nagano Prefecture, Japan; sigeharu-utiyama@suwa. irc.or.jp

Received 1 August 2004 In revised form 24 November 2004

Accepted 1 December 2004

\begin{abstract}
Objective: To correlate morphological findings of idiopathic carpal tunnel syndrome (CTS) with the function of the median nerve.

Methods: In this study, 105 wrists of 105 women patients with idiopathic CTS, and 36 wrists of 36 female volunteers were subjected to nerve conduction studies and MRI. Cross sectional area, signal intensity ratio, and the flattening ratio of the median nerve, carpal tunnel area, flexor tendon area, synovial area, and intersynovial space, and the palmar bowing of the transverse carpal ligament (TCL) were quantified by MRI and correlated with the severity of the disease determined by nerve conduction studies.

Results: Cross sectional areas of the median nerve, flexor tendons, and carpal tunnel, and the palmar bowing of the TCL of the CTS groups were greater than in the control group, but differences were not detected among the CTS groups for the area of the flexor tendons and the carpal tunnel. Enlargement, flattening, and high signal intensity of the median nerve at the distal radioulnar joint level were more significant in the advanced than in the earlier stages of the disease. Increase in palmar bowing of the TCL was less prominent in the most advanced group. Linear correlation between the area of the carpal tunnel and palmar bowing of the TCL was noted.

Conclusion: Severity of the disease could be judged by evaluating not only longitudinal changes of signal intensity and configuration of the median nerve, but also palmar bowing of the TCL. Increased palmar bowing of the TCL was found to be associated with an increase in the area of the carpal tunnel.
\end{abstract}

co diopathic carpal tunnel syndrome (CTS) is the most common entrapment neuropathy in the upper extremity; however, its aetiology remains unclear. With the development of imaging techniques, new evidence related to the carpal tunnel has been reported. ${ }^{12}$ Previous studies on the carpal tunnel using MRI compared the median nerves of patients with CTS with those of normal individuals, and determined the specific changes inside the carpal tunnel that determine diagnostic accuracy. ${ }^{2}$ Proximal swelling, flattening, and high signal intensity of the median nerve on the T2 image and an increased bowing of the transverse carpal ligament (TCL) were regarded as the characteristic findings for idiopathic CTS. $^{2-8}$ However, results were not always consistent because of differences in sample size and the inclusion of individuals with various stages of the disease or of patients of both sexes. Furthermore, quantitative analysis of the structures inside the carpal tunnel, rather than the median nerve, is very limited, although they are probably related to the pathophysiology of idiopathic CTS.

In this study, we quantified the structures inside the carpal tunnel on MRI and correlated findings with nerve conduction studies in patients with idiopathic CTS to evaluate if disease severity had an effect on morphological changes. We investigated only women because idiopathic CTS is more often seen in women than men, ${ }^{9}$ and differences in area of the flexor tendons and the carpal tunnel are known to exist between the sexes. ${ }^{10}{ }^{11}$

\section{MATERIALS AND METHODS}

We prospectively studied 105 wrists of 105 consecutive women patients diagnosed with idiopathic CTS, and 36 wrists of 36 female volunteers. Exclusion criteria for this study were history of any surgery or wrist fracture of the affected hand, double crush injury, diabetes mellitus, gout, rheumatoid arthritis, or other systemic disease. Written informed consent was obtained from all subjects, and the hospital ethics committee approved the study protocol.

All subjects underwent clinical examination, nerve conduction studies, and MRI. Posterioanterior and lateral plain $x$ ray films were taken of the affected wrist of the patients to check for bony abnormalities such as lunatomalacia, incorrect union of a distal radial fracture, bone tumour, or bony erosion. Clinical examination included Phalen's test, percussion test at the carpal tunnel, determination of area of sensory disturbance, Semmes-Weinstein monofilament test, and a pinch and grip strength test. Chronicity of the disease was determined based on the duration of numbness reported by the patients. The diagnosis of idiopathic CTS was made on the basis of medical history and physical examination. Nerve conduction studies were conducted using Neuropack MEB5504 (Nihon Kohden, Tokyo, Japan) to determine motor distal latency (MDL) and sensory conduction velocity (SCV). Details of the measurement procedure have been reported previously. ${ }^{12}$

MRI of the carpal tunnel was performed on the affected hand of the patients and the right hand of the volunteers. The protocol for the MRI was as follows: field strength,1.5 Tesla (Toshiba VISART EX, Tokyo Japan); coil type, circular extremity coil (GPFLEX); arm wrist position was prone with the arm extended over the head, the forearm in pronation, wrist in neutral position and fingers extended; and imaging direction was the axial plane from the distal radioulnar joint to the carpometacarpal joint level. Tl weighted spin echo images and $\mathrm{T} 2$ weighted gradient echo images were obtained (repetition time 600 and $380 \mathrm{~ms}$; echo time 18 and $15 \mathrm{~ms}$ for $\mathrm{T} 1$ and $\mathrm{T} 2$ respectively; section thickness, $3 \mathrm{~mm}$; intersection space, $0.3 \mathrm{~mm}$; number of signals acquired, 2 for $\mathrm{Tl}$ and 2.6

Abbreviations: CTS, carpal tunnel syndrome; MDL, motor distal latency; SCV, sensory conduction velocity; TCL, transverse carpal ligament 
Table 1 Characteristics of patients

\begin{tabular}{|c|c|c|c|c|}
\hline & \multicolumn{4}{|c|}{ Stage of carpal tunnel syndrome } \\
\hline & Control & Mild to moderate & Severe & Extreme \\
\hline Number of patients & 36 & 33 & 50 & 22 \\
\hline $\begin{array}{l}\text { Age in years, mean } \\
\text { (SD) }\end{array}$ & $46.2(7.2)$ & $53.8(10.8)$ & $\begin{array}{l}60.6(13.0) \\
p=0.015 v \text { mild to } \\
\text { moderate }\end{array}$ & $\begin{array}{l}64.4(13.1) \\
p=0.002 v \text { mild to } \\
\text { moderate }\end{array}$ \\
\hline $\begin{array}{l}\text { Wrist } \\
\text { circumference in } \\
\mathrm{mm} \text {, mean (SD) }\end{array}$ & $162.1(8.6)$ & $\begin{array}{l}166.2(7.1) \\
p=0.036 v \text { control }\end{array}$ & $\begin{array}{l}167.0(12.3) \\
p=0.044 v \text { control }\end{array}$ & $168.3(16.9)$ \\
\hline Wrist ratio & $0.66(0.03)$ & $0.67(0.04)$ & $\begin{array}{c}0.68(0.04) \\
p=0.030 v \text { control }\end{array}$ & $0.66(0.04)$ \\
\hline $\begin{array}{l}\text { Duration of } \\
\text { symptoms (months) } \\
\text { Side of the hand }\end{array}$ & & $33.3(52.3)$ & $28.7(43.3)$ & $28.0(44.7)$ \\
\hline $\begin{array}{l}\text { Right } \\
\text { Left }\end{array}$ & $\begin{array}{r}36 \\
0\end{array}$ & $\begin{array}{r}7 \\
26\end{array}$ & $\begin{array}{l}29 \\
21\end{array}$ & $\begin{array}{l}11 \\
11\end{array}$ \\
\hline Surgery & & & & \\
\hline Yes & 0 & 22 & 50 & 22 \\
\hline No & 36 & 11 & 0 & 0 \\
\hline
\end{tabular}

for T2; flip angle, $90^{\circ}$ for $\mathrm{T} 1$ and $20^{\circ}$ for $\mathrm{T} 2$; field of view, $12 \times 12 \mathrm{~cm}$; matrix, $(92 \times 256)$. Four axial image slices, perpendicular to the longitudinal line of the median nerve, were selected. Level 1 was at the distal part of the distal radioulnar joint level where the relative position of the ulnar head to the radial sigmoid notch varied due to difference in ulnar variance. Some subjects had ulnar plus variance, and others did not. We tried to select a slice that was closest to the distal sigmoid notch. Level 2 was at the middle of the pisiform. A slice that had the largest pisiform section was selected. Level 3 was at the hook of the hamate level. A slice with the longest hook of the hamate was selected. Level 4 was at the exit of the carpal tunnel. We had twelve slices for each wrist and attempted to select four slices for measurement that best met the above criteria.

Quantitative assessment was conducted for the cross sectional area, signal intensity ratio, and flattening ratio of the median nerve, flexor tendon area, carpal tunnel area, synovial area, and intersynovial space, palmar bowing of the
TCL, circumference of the wrist, and wrist ratio, using NIH Image (version 1.61; National Institutes of Health), which is a public domain image processing and analysis program. The measurements were performed on the T2 image; however, when difficulties were encountered while delineating the structure, the $\mathrm{Tl}$ image was of help. The median nerve was traced at four levels as described by Monagle. ${ }^{11}$ The signal intensity of the nerve was expressed as a ratio, which was calculated with respect to the signal intensity of the hypothenar muscles at level 4 , to avoid variations in signal that are encountered with surface coils. ${ }^{13}$ Thus, a value $<1.0$ means a higher intensity than the hypothenar muscle, and vice versa. The flattening ratio was calculated by dividing the transverse axis of the nerve by its longitudinal axis at the four levels. All flexor tendons inside the carpal tunnel, namely the flexor digitorum superficialis and profundus tendons and the flexor pollicis longus tendon, were traced at levels 2 and 3 . The carpal tunnel area at level 2 was bounded anteriorly by the TCL, laterally by the capitotrapezial ligament and the

\begin{tabular}{|c|c|c|c|c|}
\hline & Level 1: DRUJ & $\begin{array}{l}\text { Level 2: } \\
\text { pisiform }\end{array}$ & $\begin{array}{l}\text { Level 3: } \\
\text { hook of the } \\
\text { hamate }\end{array}$ & $\begin{array}{l}\text { Level 4: } \\
\text { distal TCL }\end{array}$ \\
\hline \multicolumn{5}{|l|}{ Cross sectional area $\left(\mathrm{mm}^{2}\right)$} \\
\hline Control $(n=36)$ & $9.0(2.5)$ & $9.1(2.3)$ & $8.8(1.8)$ & $8.3(2.0)$ \\
\hline Mild to moderate $(n=33)$ & $14.1(4.8)^{*}$ & $14.6(4.8)^{*}$ & $10.8(3.0)^{*}$ & $10.9(3.2)^{*}$ \\
\hline Severe $(n=50)$ & $\begin{array}{l}17.7(6.7)^{*} \\
p=0.0085^{* *}\end{array}$ & $14.6(5.6)^{*}$ & $11.2(3.3)^{*}$ & $11.4(3.5)^{*}$ \\
\hline Extreme $(n=22)$ & $\begin{array}{l}19.5(7.4)^{*} \\
p=0.0015^{* *}\end{array}$ & $14.8(5.5)^{*}$ & $10.0(3.1)$ & $10.8(3.2)^{*}$ \\
\hline \multicolumn{5}{|l|}{ Signal intensity ratio } \\
\hline Control & 3.31 (1.71) & $3.14(1.79)$ & $3.16(1.86)$ & $3.47(1.73)$ \\
\hline Mild to moderate & $2.08(1.02)^{*}$ & $\begin{array}{r}2.07(1.02) \\
p=0.0038^{*}\end{array}$ & $2.54(1.27)$ & $\begin{array}{l}2.50(1.07) \\
p=0.008^{*}\end{array}$ \\
\hline Severe & $\begin{array}{c}1.45(1.07)^{*} \\
p=0.0093^{*}\end{array}$ & $1.86(1.40)^{\star}$ & $\begin{array}{l}2.36(1.44) \\
p=0.026^{*}\end{array}$ & $\begin{array}{c}2.36(1.41) \\
p=0.0018^{*}\end{array}$ \\
\hline Extreme & $1.24(0.58)^{* * *}$ & $\begin{array}{c}1.78(1.40) \\
p=0.0037^{*}\end{array}$ & $2.43(1.31)$ & $\begin{array}{c}2.35(1.06) \\
p=0.0086^{*}\end{array}$ \\
\hline \multicolumn{5}{|l|}{ Flattening ratio } \\
\hline Control & $2.14(0.41)$ & $2.33(0.52)$ & $2.63(0.67)$ & $3.04(0.70)$ \\
\hline Mild to moderate & $2.38(0.61)$ & $\begin{aligned} 2.62(0.55)^{*} \\
p=0.0245\end{aligned}$ & $2.76(0.75)$ & $2.87(0.55)$ \\
\hline Severe & $2.56(0.49)^{*}$ & $2.84(0.55)^{*}$ & $2.53(0.61)$ & $2.77(0.74)$ \\
\hline Extreme & $2.64(0.42)^{*}$ & $2.92(0.63)^{*}$ & $2.62(0.87)$ & $2.94(1.19)$ \\
\hline
\end{tabular}


Table 3 Palmar bowing of the TCL and cross sectional area of the flexor tendons, synovial space, and carpal tunnel

\begin{tabular}{|c|c|c|}
\hline & $\begin{array}{l}\text { Level 2: } \\
\text { pisiform }\end{array}$ & $\begin{array}{l}\text { Level 3: } \\
\text { hook of the } \\
\text { hamate }\end{array}$ \\
\hline \multicolumn{3}{|l|}{ Flexor tendon area $\left(\mathrm{mm}^{2}\right)$} \\
\hline Control $(n=36)$ & $69.1(7.7)$ & $72.0(8.6)$ \\
\hline Mild to moderate $(n=33)$ & $76.4(8.3)^{*}$ & $\begin{array}{l}78.7(8.2) \\
p=0.0016^{*}\end{array}$ \\
\hline \multirow[t]{2}{*}{ Severe $(n=50)$} & $75.7(9.6)$ & $77.1(9.3)$ \\
\hline & $p=0.001^{*}$ & $p=0.0126^{\star}$ \\
\hline Extreme $(n=22)$ & $\begin{array}{l}74.6(8.9) \\
p=0.0157^{*}\end{array}$ & $77.0(10.6)$ \\
\hline \multicolumn{3}{|c|}{ Synovial and intersynovial space $\left(\mathrm{mm}^{2}\right)$} \\
\hline Control & $86.5(13.3)$ & $65.6(8.0)$ \\
\hline Mild to moderate & $92.5(14.4)$ & $67.3(12.2)$ \\
\hline Severe & $90.0(15.0)$ & $65.1(10.7)$ \\
\hline \multirow{2}{*}{\multicolumn{3}{|c|}{ Carpal tunnel area $\left(\mathrm{mm}^{2}\right)$}} \\
\hline & & \\
\hline Control & $164.6(16.6)$ & $\begin{array}{l}146.3(13.1) \\
136.4(13.1) \dagger\end{array}$ \\
\hline Mild to moderate & $183.5(16.8)^{*}$ & $\begin{array}{l}156.8(15.6) \\
p=0.0035^{*} \\
136.4(17.5) \dagger\end{array}$ \\
\hline Severe & $180.3(19.3)^{*}$ & $\begin{array}{l}153.4(15.4) \\
p=0.0287^{*} \\
132.2(13.0) t\end{array}$ \\
\hline Extreme & $174.2(22.1)$ & $\begin{array}{l}150.0(16.3) \\
131.1(15.9) \dagger\end{array}$ \\
\hline \multicolumn{3}{|l|}{ Palmar bowing (mm) } \\
\hline \multirow{2}{*}{\multicolumn{2}{|c|}{$\begin{array}{l}\text { Control } \\
\text { Mild to moderate }\end{array}$}} & $1.29(0.78)$ \\
\hline & & $2.58(0.82)^{*}$ \\
\hline \multicolumn{2}{|l|}{ Severe } & $2.78(0.85)^{*}$ \\
\hline Extreme & & $\begin{array}{l}2.26(0.84)^{*} \\
p=0.0182^{* *}\end{array}$ \\
\hline \multicolumn{3}{|c|}{$\begin{array}{l}\text { All values are expressed as means (SD). }{ }^{*} p<0.05 \text { versus control, } \\
{ }^{* *} p<0.05 \text { versus severe. The } p \text { value is not shown if }<0.001 \text {. } † \text { Carpal } \\
\text { tunnel area in the absence of palmar bowing of the TCL. TCL, transverse } \\
\text { carpal ligament. }\end{array}$} \\
\hline
\end{tabular}

scaphoid, medially by the pisiform, and dorsally by the carpal bones and the intercarpal ligament; that at level 3 was bounded anteriorly by the TCL, laterally by the capitotrapezial ligament and the scaphoid, medially by the hook of the hamate, and dorsally by the carpal bones and the intercarpal ligaments. The synovial area and intersynovial space were calculated by subtracting the flexor tendon area and median nerve area from the carpal tunnel area. The palmar bowing of the TCL was defined as the perpendicular distance to the TCL from the line between the hook of the hamate and the trapezium at level 3. The carpal tunnel area in the absence of palmar bowing of the TCL at level 3 was measured to assess the initial carpal tunnel area. The circumference of the wrist was measured at level 1 to assess wrist size. We calculated the wrist ratio by dividing the anteroposterior diameter by the transverse diameter at level 1. Each measurement described above was repeated three times, and the average values were used for data analysis. All measurements were rated by a single researcher (SU).

A small reproducibility exercise using pairs of repeated measurements on the median nerve cross sectional area at the level 1 of five patients showed no evidence of a systematic difference between occasions (paired $t$ test $\mathrm{p}=0.6300$ ) and the intraclass correlation coefficient of $97.5 \%$ showed that errors of observation would contribute about $2.5 \%$ to the variation between subjects such as these. This reduced the sensitivity and power of the analyses, but not enough to matter with a sample of this size.

Severity of the disease was determined on the basis of nerve conduction velocities. This classification was similar to that of Padua et al ${ }^{14}$ as follows. Normal: MDL $<4.4 \mathrm{~ms}$, SCV $\geqslant 44 \mathrm{~m} / \mathrm{s}$; mild: MDL $<4.4 \mathrm{~ms}$ and SCV $<44 \mathrm{~m} / \mathrm{s}$; moderate:
$\mathrm{MDL} \geqslant 4.4 \mathrm{~ms}$ and $\mathrm{SCV}<44 \mathrm{~m} / \mathrm{s}$; severe: $\mathrm{MDL} \geqslant 4.4 \mathrm{~ms}$ and no response of SCV; extreme: no response of MDL and SCV. Based on the severity of the disease, the hands were classified into four groups: normal, mild to moderate CTS, severe CTS, and extreme CTS. The mild to moderate, severe, and extreme were regarded as CTS groups, and the normal group as the control.

Each parameter was compared between four different groups, using Student's $t$ test. The correlation coefficient between the average area of the carpal tunnel at levels 2 and 3 and palmar bowing of the TCL was calculated, as was that between the circumference of the wrist and palmar bowing of the TCL for both the control and CTS groups. Statistical significance was achieved when the $\mathrm{p}$ value was $<0.05$.

\section{RESULTS}

Characteristics of the hands are shown in table 1. Carpal tunnel release surgery was performed on 94 wrists. Symptoms either disappeared or were relieved, and an improvement of nerve conduction velocities was confirmed after surgery.

Details of data of the cross sectional area, signal intensity ratio, and flattening ratio of the median nerve, the cross sectional area of the flexor tendons, synovium and intersynovial space, and the carpal tunnel, and the palmar bowing of the TCL are shown in tables 2 and 3.

In the control group, the cross sectional area of the median nerve and signal intensity ratio were constant throughout the levels, but flattening was more significant at level 4 than at the other levels. In the mild to moderate group, the cross sectional area was larger than in the control group in all slices, and the flattening ratio did not differ from the control group except at level 2 . Cross sectional area at the proximal two levels was larger than at the distal two levels, and was accompanied by a lower signal intensity ratio (higher signal intensity) than the distal. In the severe and extreme groups, the cross sectional area was progressively larger proximally from level 3, and was accompanied by a high signal intensity. The flattening ratio was larger than the control group at levels 1 and 2. At level 3, the flattening ratio did not differ from the control group. Although the flexor tendon area and the carpal tunnel area were larger in the CTS groups than in the control group, significant differences were not detected among the CTS groups. Palmar bowing of the TCL was also greater in the CTS groups than in the control group, but the increase was less prominent in the extreme than in the severe group. No significant difference of synovial space and intersynovial area was detected among the groups. Figure 1 shows the carpal tunnel cross sections of the control, mild to moderate, and extreme groups.

A significant linear correlation between the average area of the carpal tunnel at levels 2 and 3 and palmar bowing of the TCL was noted for the CTS groups (correlation coefficient $0.489, \mathrm{p}<0.0001)$, but not for the control group (0.154, $\mathrm{p}=0.374$ ). A significant correlation between the circumference of the wrist and palmar bowing of the TCL was not found for either the CTS or the control groups (0.067, $p=0.497$ for the CTS; $0.16, p=0.353$ for the control).

When the carpal tunnel area was measured in the absence of palmar bowing of the TCL, no significant difference was detected among the groups ( $p>0.1448$; table 3$)$.

\section{DISCUSSION}

The aetiology of idiopathic CTS may be attributed to an incompatibility between the median nerve and carpal tunnel. ${ }^{15}{ }^{16}$ As a result, the intracarpal tunnel pressure increases, ${ }^{17}$ and disturbance of circulation to the nerve occurs. Longstanding epineurial oedema leads to invasion of fibroblasts and subsequent formation of constricting scar 

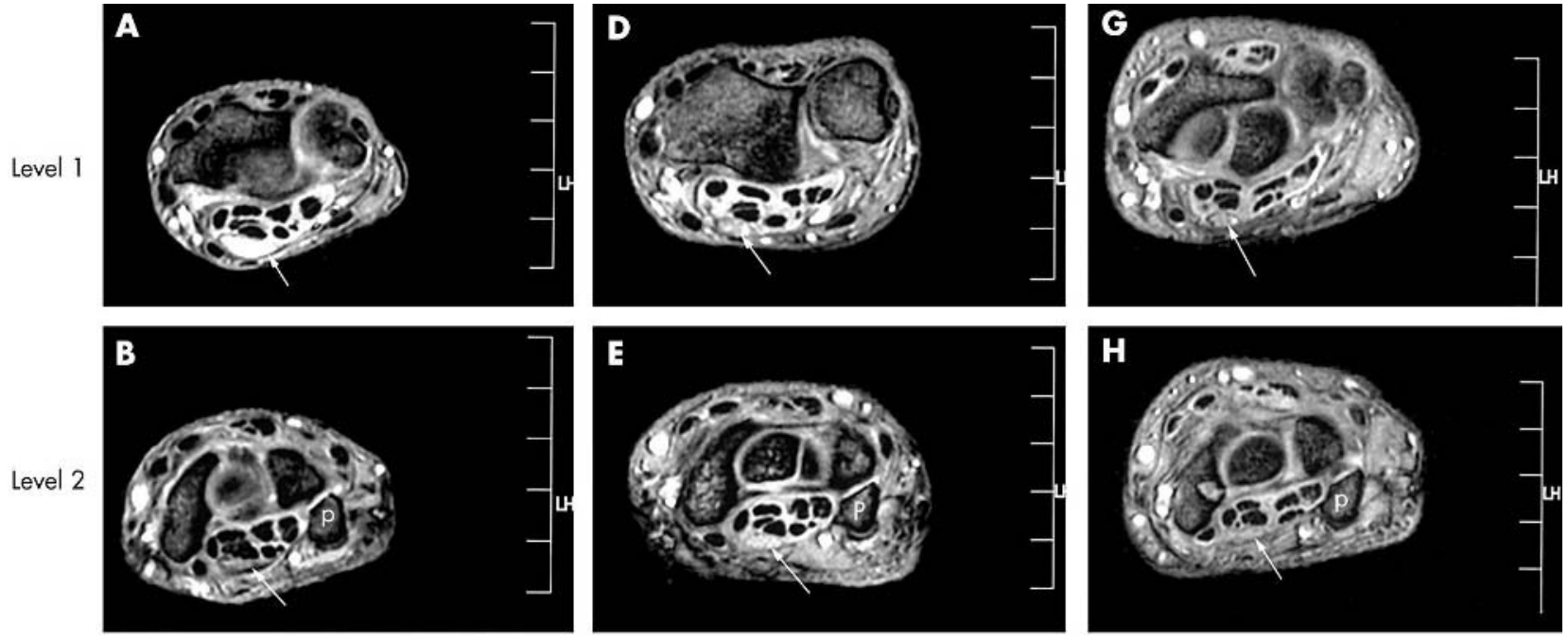

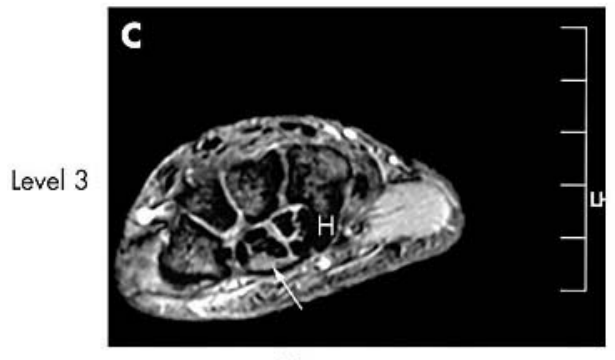

Extreme

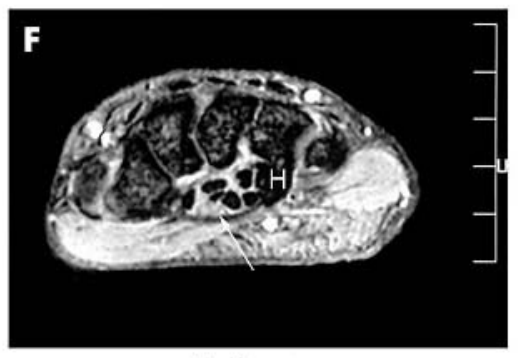

Moderate

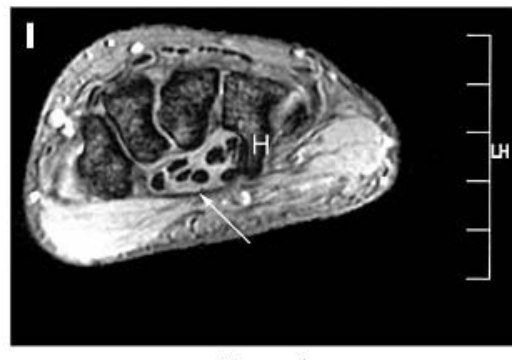

Normal

Figure 1 T2 weighted gradient echo images at the distal part of the distal radioulnar joint level (DRUJ) (1), at the level of the pisiform (2) and at the level of the hook of the hamate (3) in three different stages of idiopathic carpal tunnel syndrome. Solid arrow indicates the cross section of the median nerve. Upper part represents the dorsal side, and the righthand side represents the ulnar side. $\mathrm{P}$, pisiform bone; $\mathrm{H}$, hook of the hamate. (A-C) Extreme stage. Enlargement and high signal intensity of the flattened median nerve are seen at level 1, and enlargement of the median nerve at levels 2 and 3. Palmar bowing of the TCL is evident. (D-F) Moderate stage. Enlargement and high signal intensity of the median nerve are seen at level 2. They are slightly appreciated at level 3, and still not seen at level 1. Palmar bowing of the TCL is well appreciated. (G-I) Normal wrist. Enlargement of the median nerve is not seen at any level. Isointensity of the nerve to the hypothenar muscle is seen throughout the cross sections. Palmar bowing of the TCL is not seen.

tissue inside the nerve. ${ }^{15}$ Swelling of the nerve trunk proximal to the compression site is due to an increase in the amount of endoneurial connective tissue, ${ }^{18}$ oedema in the epineurium and endoneurial space, and obstruction of axoplasmic flow. ${ }^{15}$ Macroscopic configuration of the median nerve during open carpal tunnel surgery has varied; however, conventionally proximal enlargement of the median nerve, or pseudoneuroma was believed to result from compression in the distal carpal tunnel, indicating a reduction in the size of the nerve or flattening of the nerve at the hook of the hamate level. ${ }^{18-21}$

Imaging techniques can be used to detect these morphological changes. ${ }^{17}$ Using cadaveric specimens, MRI has been shown to be a valid and reproducible technique for measuring carpal tunnel volume and the cross sectional area of the flexor tendons and the median nerve. ${ }^{22}{ }^{23}$ Because the pathophysiology varies with the disease stage, ${ }^{15}$ disease severity can affect the imaging outcome. ${ }^{12}$

Configuration of the median nerve is the parameter most widely investigated not only by MRI, but also by ultrasonography, because delineation of this nerve is easy. Enlargement of the cross sectional area of the median nerve at the proximal carpal tunnel or at the entrance to the tunnel was found to be of diagnostic value for idiopathic CTS in the majority of cases studied. ${ }^{134711132425}$ However, several investigators have shown a larger cross sectional area of the nerve in CTS groups than in controls.even at the hook of the hamate level ${ }^{4}{ }^{11}$ Kleindienst et al demonstrated that oedema of the nerve resulted in pre-stenotic swelling and moderate intracarpal swelling, and that the advanced stages of CTS showed retrograde swelling of the median nerve more than the earlier stages. ${ }^{25}$ Our results were nearly consistent with these results.

There have been inconsistencies in results regarding the flattening ratio of the median nerve among investigators. Some found no difference between the idiopathic CTS groups and controls; ${ }^{1126}$ however, others have shown that the median nerve was more flattened at the level of the hook of the hamate in CTS groups than in control subjects. ${ }^{4}{ }^{13}$ In our study, no significant difference was detected at this level, but the large standard deviation of the flattening ratio indicated that the median nerve configuration varied even within the same disease stage, indicating that the median nerve did not always have a compressive deformity at this level. The median nerve was flattened at the level of exit of the TCL for all CTS groups and the control group, because furcation of the nerve could be observed at this level. Our results suggest that inconsistencies among previous studies in the flattening ratio were due to differences in patient spectra or pathophysiology, or both.

T2 MRI presents the normal nerve as isointensity, and it may develop a high signal intensity when it is damaged or degenerated..$^{27}{ }^{28}$ The increased nerve signal on T2 MRI is due to interstitial oedema and the collapse and loss of myelinated fibres. ${ }^{29}$ Preoperative high signal intensity of the median nerve on T2 may be a meaningful finding for idiopathic CTS, 
because it decreases after surgical decompression of the nerve. ${ }^{451330}$ Because the signal intensity ratio was found to be inversely proportional to the area of the median nerve, the enlargement of the median nerve was associated with higher water content or more degeneration inside the nerve than in the normal nerve. Bulbous swelling of the median nerve at the level proximal to the carpal tunnel that is often observed during surgeries could be a characteristic finding of the advanced stages of the disease. In our study, this swelling was often accompanied by higher signal intensity than the distal level, suggesting oedema and degeneration of the nerve. However, signal intensity could be decreased in the advanced CTS because of fibrosis within the nerve. ${ }^{25}$

Quantification of the flexor tendon area was only performed in studies by Monagel and Cobb. ${ }^{11}{ }^{31}$ Monagel found no differences in the flexor tendon area between CTS patients and normal subjects. ${ }^{11}$ Cobb et al showed increased carpal tunnel contents (flexor tendon and median nerve) to carpal tunnel volume ratios in CTS compared with controls. ${ }^{31}$ As the number of hands analysed was small in both studies, no definitive conclusions could be made. In our study, we were not sure if the enlargement of the flexor tendons was congenital, or the result of the disease. Differences in flexor tendon size between CTS groups and control subjects remain to be clarified.

Phalen believed that thickening or fibrosis of the synovium was the main cause of idiopathic CTS. ${ }^{20}$ This is believed to be due to an increased volume of the carpal tunnel contents or the result of swelling by repetitive motion of the digits, which leads to chronic tenosynovial thickening and fibrosis. ${ }^{32}$ Britz et $a l^{5}$ and Zagnoli et $a l^{8}$ assessed the synovium inside the carpal tunnel by evaluating the interspace or the distance between the flexor tendons by MRI. Their studies involved a qualitative analysis, and interobserver variation was found to be considerable. We did not find any differences in area between the CTS groups and the control group. However, with our method it was difficult to evaluate subtle changes of synovium or subsynovial connective tissue, which may have an important role in development of idiopathic CTS. ${ }^{33}$

The size of the carpal tunnel area has been measured by MRI and CT, but the results were inconsistent. Some showed a larger carpal tunnel area in patients than in controls, ${ }^{34}$ but others did not. ${ }^{35}{ }^{36}$ Our result indicated that the area at the proximal and the distal carpal tunnel was significantly larger in all groups except in the extreme group than it was in the control group. Previous investigators believed that palmar bowing of the TCL was greater in idiopathic CTS groups than in the control subjects. ${ }^{4811}$ Our result was consistent with that belief. In such cases, some structure inside the carpal tunnel is needed to push the TCL in a volar direction. However, few studies have correlated this parameter with the carpal tunnel area. Monagel et al did not find any difference between carpal tunnel areas, but showed that palmar bowing differed between the CTS and control groups. ${ }^{11}$ We showed a significant linear correlation between the area of the carpal tunnel and palmar bowing of the TCL for the CTS groups, but not for the control group. Furthermore, palmar bowing of the TCL did not have a linear correlation with wrist size in either group. These results suggest that increased palmar bowing of the TCL is a characteristic of idiopathic CTS, resulting from an increase in the area of the carpal tunnel. It may be a result of the disease, not a difference in the initial carpal tunnel area, as the carpal tunnel area in the absence of palmar bowing of the TCL of the CTS groups was the same as that of the control group. The increased area of the carpal tunnel could be due to flexor tendons and the median nerve. Because synovial evaluation was difficult to perform in this study, the involvement of the synovium with enlargement of the carpal tunnel remains to be clarified.
Palmar bowing of the TCL could also be useful to assess disease severity because it was less prominent in the extreme than the severe group. This may be due to decreased tissue swelling such as swelling of the median nerve inside the carpal tunnel, as severity progresses, because the median nerve area and the carpal tunnel area of the extreme group was not as large as in the other CTS groups at the level of the hook of the hamate.

Based on this study, which quantitatively analysed the largest number of female subjects ever examined, the increased palmar bowing of the TCL was found to be due to an increase in the area of the carpal tunnel in idiopathic CTS. Although enlargement of the carpal tunnel area and the flexor tendon area could be characteristic findings for idiopathic CTS on T2 MRI, severity of the disease was difficult to judge using those parameters. It could be best judged by evaluating palmar bowing of the TCL and longitudinal changes in signal intensity and in the configuration of the median nerve.

This study may explain the reason for inconsistencies in previous studies and help to elucidate the pathophysiology of idiopathic CTS. However, there are some limitations to this study. As some variations were observed within the same group, there could be differences in pathophysiology inside the carpal tunnel of individuals, even in a relatively uniform group of subjects, all of whom were clinically diagnosed with idiopathic CTS. It would have been better to enrol patients with minimum neurophysiological abnormalities such as Padua's minimal stage, ${ }^{14}$ because much of the remaining uncertainty over the use of imaging in CTS concerns whether imaging modalities add anything when the neurophysiological abnormalities are minimal. The effect of aging on changes of the median nerve and flexor tendon configuration has not been studied by MRI, and high signal intensity on T2 images could not be always specific. Because we performed endoscopic carpal tunnel release in many patients in this study, we did not correlate the status of the structures inside the carpal tunnel during surgery with the preoperative MRI. The many statistical tests could cause some significant findings to arise by chance, thus the $p$ values should simply be used as an indication of the strength of a particular piece of evidence.

\section{ACKNOWLEDGEMENT}

We thank Dr K Yamashita Department of Radiology, Suwa Red Cross Hospital, for his advice on the MRI protocol and on the interpretation of images, and also Mr T Muramatsu, Imaging Technology Center, Suwa Red Cross Hospital, for his effort to improve the quality of the MRI of the wrist. We thank the nurses in Suwa Red Cross Hospital for their willingness to participate in this study.

\section{Authors' affiliations}

S Uchiyama, T Itsubo, H Nakagawa, M Kamimura, Department of Orthopaedic Surgery, Suwa Red Cross Hospital, Suwa City, Japan T Yasutomi, Department of Orthopaedic Surgery, Shiokawa Hospital, Sutama, Japan

H Kato, Department of Orthopaedic Surgery, Shinshu University School of Medicine, Matsumoto City, Japan

Competing interests: none declared

\section{REFERENCES}

1 Nakamichi K, Tachibana S. Enlarged median nerve in idiopathic carpal tunnel syndrome. Muscle Nerve 2000;23:1713-18.

2 Pasternack II, Malmivaara A, Tervahartiala P, et al. Magnetic resonance imaging findings in respect to carpal tunnel syndrome. Scand J Work Environ Health 2003;29:189-96.

3 Jarvik JG, Yuen E, Haynor DR, et al. MR nerve imaging in a prospective cohort of patients with suspected carpal tunnel syndrome. Neurology 2002;58:1597-602.

4 Allmann $\mathrm{KH}$, Horch R, Uhl M, et al. MR imaging of the carpal tunnel. Eur J Radiol 1997;25:141-5. 
5 Britz GW, Haynor DR, Kuntz C et al. Carpal tunnel syndrome:correlation of magnetic resonance imaging, clinical, electrodiagnostic, and intraoperative findings. Neurosurgery 1995; 37:1097-103.

6 Deryani E, Aki S, Muslumanoglu L, et al. MR imaging and electrophysiological evaluation in carpal tunnel syndrome. Yonsei Med J 2003:44:27-32.

7 Mesgarzadeh M, Triolo J, Schneck CD. Carpal tunnel syndrome. MR imaging diagnosis. Magn Reson Imaging Clin N Am 1995;3:249-64.

8 Zagnoli F, Andre V, Dreff PL, et al. Idiopathic carpal tunnel syndrome. Clinical, electrodiagnostic, and magnetic resonance imaging correlations. Rev Rhum 1999;66:192-200.

9 Treaster DE, Burr D. Gender differences in prevalence of upper extremity musculoskeletal disorders. Ergonomics 2004;47:495-526.

10 Dekel S, Papaioannou T, Rushworth G, et al. Idiopathic carpal tunnel syndrome caused by carpal stenosis. BMJ 1980;280:1297-9.

11 Monagle K, Dai G, Chu A, et al. Quantitative MR imaging of carpal tunnel syndrome. AJR 1999;172:1581-6.

12 Uchiyama S, Toriumi $\mathrm{H}$, Nakagawa $\mathrm{H}$, et al. Postoperative nerve conduction changes after open and endoscopic carpal tunnel release. Clin Neurophysiol 2002;113:64-70.

13 Cudlip SA, Howe FA, Clifton A, et al. Magnetic resonance neurography studies of the median nerve before and after carpal tunnel decompression. J Neurosurg 2002;96:1046-51.

14 Padua L, LoMonaco M, Gregori B, et al. Neurophysiological classification and sensitivity in 500 carpal tunnel syndrome hands. Acta Neurol Scand 1997;96:211-17.

15 Lundborg G. Nerve entrapment. In: Lundborg G, ed. Nerve injury and repair Edinburgh London Melbourne and New York: Churchill Livingstone, 1988:102-48.

16 Hart AM, Wiberg M. Nerve compression or mechanical neuropathy: neuropathology. Curr Orthopaed 2001;15:245-8.

17 Gelberman RH, Hergenroeder PT, Hargens AR, et al. The carpal tunnel syndrome. A study of carpal canal pressures. J Bone Joint Surg 1981;63A:380-3.

18 Thomas PK, Fullerton PM. Nerve fibre size in the carpal tunnel syndrome. J Neurol Neurosurg Psychiatry 1963;26:520-27.

19 Goodman HV, Gilliatt RW. The effect of treatment on median nerve conduction in patients with the carpal tunnel syndrome. Ann Phys Med $1961 ; 6: 137-55$.

20 Phalen GS. The carpal-tunnel syndrome: seventeen years' experience in diagnosis and treatment of six hundred fifty-four hands. J Bone Joint Surg 1966;48A:211-28
21 Tanzer RC. The carpal tunnel syndrome: a clinical and anatomical study. J Bone Joint Surg 1959;41A:624-34.

22 Richman JA, Gelberman RH, Rydevik BL, et al. Carpal tunnel volume determination by magnetic resonance imaging three-dimensional reconstruction. J Hand Surg 1987;12A:712-17.

23 Cobb TK, Dalley BK, Posteraro RH, et al. Establishment of carpal contents/ canal ratio by means of magnetic resonance imaging. $J$ Hand Surg 1992;17A:843-9.

24 Kele $\mathrm{H}$, Verheggen $\mathrm{R}$, Bittermann $\mathrm{HJ}$, et al. The potential value of ultrasonography in the evaluation of carpal tunnel syndrome. Neurology 2003;61:389-91.

25 Kleindienst A, Hamm B, Lanksch WR. Carpal tunnel syndrome: staging of median nerve compression by MR imaging. JMRI 1998;8:1119-25.

26 Bak L, Bak S, Gaster P, et al. MR imaging of the wrist in carpal tunnel syndrome. Acta Radiol 1997;38:1050-2.

27 Dailey AT, Tsuruda JS, Filler AG, et al. Magnetic resonance neurography of peripheral nerve degeneration and regeneration. Lancet 1997;350:1221-2.

28 Teresi $L M$, Hovda D, Seeley AB, et al. MR imaging of experimental demyelination. Am J Radiol 1989;152:1291-8.

29 Does MD, Snyder RE. Multiexponential T2 relaxation in degenerating peripheral nerve. Magn Reson Imaging 1996;35:207-13.

30 Pierre-Jerome C, Bekkelund SI, Mellgren SI, et al. Bilateral fast magnetic resonance imaging of the operated carpal tunnel. Scand J Plast Reconstr Hand Surg 1997;31:171-7.

31 Cobb TK, Bond JR, Cooney WP, et al. Assessment of the ratio of carpal contents to carpal tunnel volume in patients with carpal tunnel syndrome: a preliminary report. J Hand Surg 1997;22A:635-9.

32 Shum C, Parisien M, Strauch RJ, et al. The role of flexor tenosynovectomy in the operative treatment of carpal tunnel syndrome. J Bone Joint Surg 2002;84A:221-5.

33 Ettema AM, Amadio PC, Zhao C, et al. A histological and immunohistochemical study of the subsynovial connective tissue in idiopathic carpal tunnel syndrome. J Bone Joint Surg 2004;86A:1458-66.

34 Winn FJ Jr, Habes DJ. Carpal tunnel area as a risk factor for carpal tunnel syndrome. Muscle Nerve 1990;13:254-8.

35 Bleecker ML, Bohlman M, Moreland R, et al. Carpal tunnel syndrome:role of carpal canal size. Neurology 1985;35:1599-604.

36 Pierre-Jerome C, Bekkelund SI, Mellgren SI, et al. Quantitative MRI and electrophysiology of preoperative carpal tunnel syndrome in a female population. Ergonomics 1997;40:642-9. 